\title{
The Practice of Transboundary Decision Making on the Incomati River: Elucidating Underlying Factors and their Implications for Institutional Design
}

\author{
$\underline{\text { Jill H. Slinger }}^{1}, \underline{\text { Marianne Hilders }}^{2}$, and $\underline{\text { Dinis Juizo }}^{3}$
}

\begin{abstract}
The Incomati River Basin is shared by Mozambique, South Africa, and Swaziland. In August 2002, the groundbreaking "Tripartite Interim Agreement on Water Sharing of the Maputo and Incomati Rivers" (the IncoMaputo agreement) was signed. Following reports that the use, availability, and adequacy of information posed problems for future decision making on this transboundary river, the Delft University of Technology initiated a 6-month study in 2003 in which 25 southern African researchers and officials were interviewed. The Joint Incomati Basin Study (Phase I from 1992-1995, and Phase II from 20002001) formed a central component in the investigation, because it was viewed by the parties involved as a successful experience that paved the way for the IncoMaputo agreement. Knowledge of the role that information played in this process and how decision making occurred was collated and analyzed. Network theory provided the guiding theoretical framework in interpreting the results. A number of problems related to information use in decision making were identified. More importantly, a web of underlying causes was identified, such as cultural and language differences, differences in perception, inadequacy of stakeholder involvement, variability in political commitment, lack of capacity, absence of operational experience, the weak mandate of the international decision-making body, and the paradoxical South African-Mozambican relationship. Two groups of factors in this web were identified as needing to change if the management of this transboundary river is to comply with the IncoMaputo agreement, namely the situational or institutional factors and the cognitive factors (particularly the perceptions each country holds of the other and the way they treat one another). Our analysis shows that, contrary to current international practice, when designing international institutional arrangements for water management, the sociopolitical interface should be considered as important as information flow to the water managers.
\end{abstract}

Key Words: causal analysis; decision making; governance; information use; institutions; international water policy; Mozambique; networks; river-basin management; South Africa; southern Africa; Swaziland

\section{INTRODUCTION}

A recent review of existing transboundary watermanagement structures and practices in Europe concluded that "problems of communication and information exchange among different levels of governance as well as across borders present major difficulties for water policy implementation" (Timmerman and Interwies 2007). This view is further endorsed by studies demonstrating the need for social learning to improve the adaptiveness of water-governance institutions and their responsiveness to uncertainty (Pahl-Wostl 2007). Indeed, Lejano and Ingram (2007) pay attention to the role of social networks in increasing the robustness of watermanagement institutions, and there is a deepening of understanding about the barriers that cultures introduce to public participation (Enserink et al. 2007). These and many other factors influence institutional arrangements for the management of transboundary rivers (Mostert et al. 2007, Raadgever et al. 2008). However, rather than exploring the role of (new) institutions (organizations, norms, or rules, etc.) in inducing more integrated transnational management in the future, the focus of our work is on learning from the practice of decision making on the Incomati River in southern Africa in the past. Knowledge gained 
from a historical analysis can facilitate the identification of underlying issues crucial to the problems experienced by decision makers today, and thus permit social learning.

The Incomati River Basin is shared by Swaziland, Mozambique, and South Africa (Fig. 1). The river provides for a variety of development needs in a tropical region subject to climatic extremes varying between severe droughts and floods. In August 2002, history was made with the signing of the "Tripartite Interim Agreement on Water Sharing of the Maputo and Incomati Rivers (IIMA)" (Tripartite Permanent Technical Committee (TPTC) 2002). This agreement followed up on the revised "Protocol on Shared Watercourses" promulgated by the Southern African Development Community (SADC) in 2000. It is unique in Africa and the world. It is the first elaborate water-sharing agreement based on the principles of integrated water management of the Dublin and Rio de Janeiro declarations (International Conference on Water and the Environment (ICWE)1992, United Nations Conference on Environment and Development (UNCED) 1992) and the UN "Convention on the Law of Non-navigational Uses of International Watercourses" (United Nations (UN) 1997), negotiated solely by the countries involved in such a transboundary situation.

Despite this successful negotiation process, all parties recognize that decision making on the Incomati had not run smoothly in the past. The agreement was preceded by several studies, for example, the Joint Incomati Basin Study (JIBS) (Consultec and BKS Acres 2001). However, the extent to which these studies informed the agreement remains unclear. There is a call for institutional reform, including the founding of a River-Basin Organization. However, even to proponents of such institutional reform, it is unclear precisely what improvements in decision making this could achieve. Indeed, it is unclear how international decision making on the Incomati actually takes place and what role information plays in this process. Given that the IIMA is currently in the implementation phase, and that initially the countries had agreed to a review date set for 2006 (TPTC 2002), it has become important to identify what improvements need to be made to ensure effective implementation and whether institutional reform is necessary. Notwithstanding the progress in the implementation of the joint water-resources assessment of the Maputo river, other aspects of the
IIMA have since experienced significant delays in implementation and deadlines have passed without noteworthy progress.

We adopt an information perspective in a historical analysis of international decision making on the Incomati River. Problems related to the use, availability, and adequacy of information for decision making are specified in a focused analysis of the JIBS. By interpreting the findings of the study primarily in the light of agenda-setting theory and network governance (Kingdon 1984/1995, Lindblom 1993, Rhodes 1996, van Bueren et al. 2001, Koppenjan and Klijn 2004, Klijn 2008), we are able to elucidate a number of causes of the limited use of information in the transboundary management of the Incomati. The complex nature of the interactions among these causal factors, as well as the focus of our work on an in-depth analysis of a particular case study, does not allow us fully to generalize our findings regarding institutional arrangements. However, we are able to distinguish a particular design element as being critical to successful international decision making. Indeed, we emphasize that in designing institutional arrangements to support transboundary decision making, the sociopolitical interface is as important as information flow to the water managers.

\section{METHODS}

This research effort was initiated in 2003 by the Delft University of Technology in response to the identification of information use as a problematic issue in international water management and related policy formulation by the Mozambicans, South Africans, and Swazis involved in a cross-national workshop in 2001 (Slinger and De Groen 2001). The necessity of establishing whether this was a new or persistent problem, and of assessing its implications for future decision making, led us to select a study method that accommodated a historical perspective while also taking the knowledge of the current decision makers into account.

A three-stage approach was designed in which a historical analysis of available literature was followed by the selection and in-depth analysis of a case study and by an analysis of current perspectives. The case study was selected using criteria derived from the historical analysis. These criteria pointed to the need for a recently completed, 
Figure 1. Map of the Incomati River Basin (after Consultec and BKS Acres 2001).

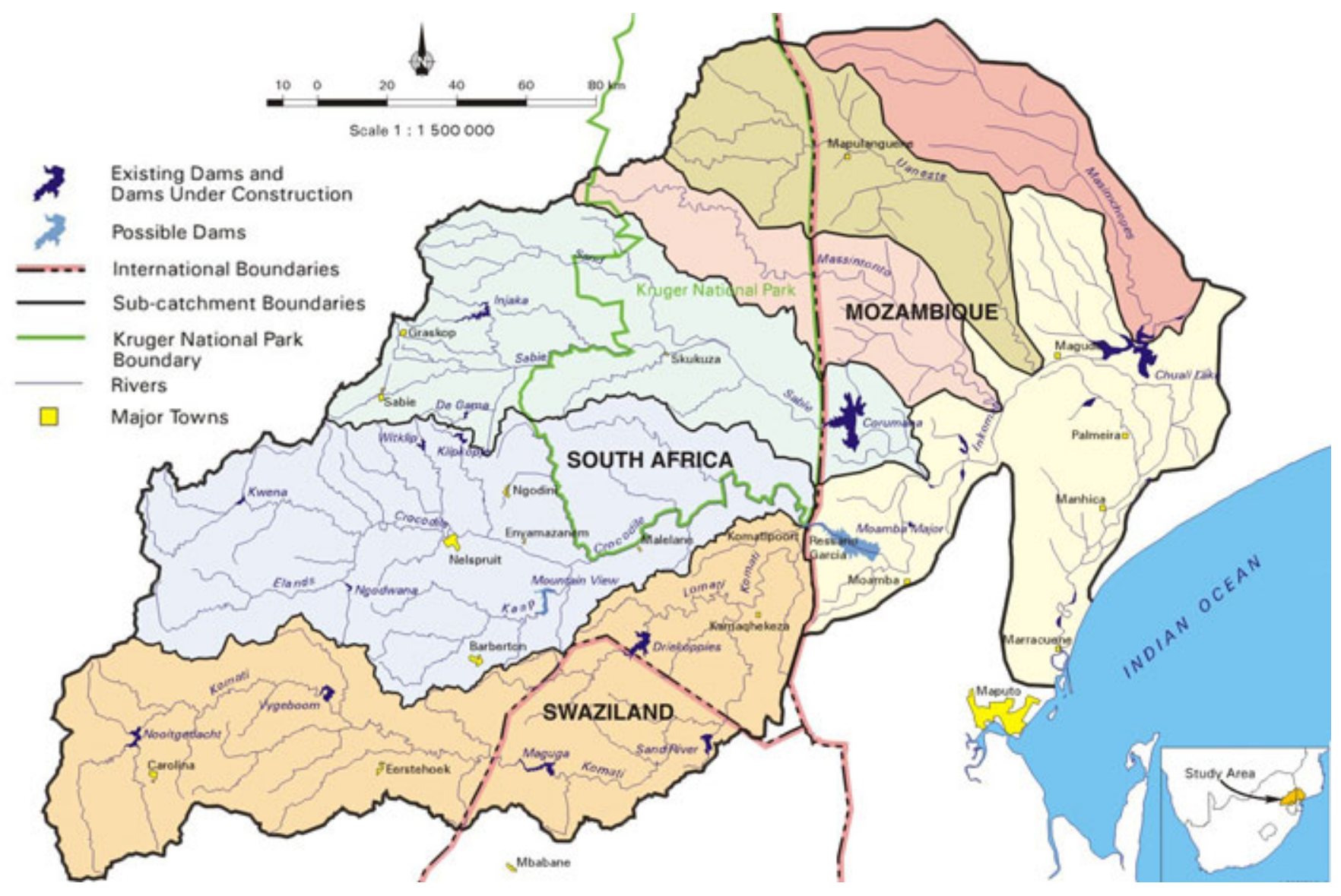

information-rich study that was influential in policy circles on the Incomati. This information richness was necessary to provide sufficient material for indepth analysis. The recent completion was a necessary factor to ensure that the case study could act as a pivot between the historical analysis and the present experiences of decision makers on the Incomati River. The study also needed to be acknowledged as useful by the decision makers so that positive, rather than only negative, lessons relevant to policy development could be drawn from the analysis. These criteria resulted in the selection of the JIBS as the case study.

An evaluation of the JIBS was undertaken using a list of criteria for evaluating policy analytic activities (Table 1). The criteria followed this division: input, content, process, results, use, and effects (Thissen and Twaalfhoven 2001).
Information on the JIBS was garnered from relevant literature and interviews on the current formal situation, the research network, the gap between policies and practice, information use in the process, problems people have at different levels concerning information or concerning the working structure, and opinions about institutional structures. The selection of interviewees was based on their involvement with the Tripartite Permanent Technical Committee (TPTC) and their provision of information on the Incomati River study. A plan to interview TPTC members at the ministerial level had to be abandoned because of busy time schedules and the logistical difficulties associated with conducting 25 interviews in three different countries within a limited period. Instead, semistructured interviews were conducted with water managers and decision makers at national and subnational levels, and with scientists involved in international, water, 
Table 1. Criteria used in the evaluation of the Joint Incomati Basin Study.

\begin{tabular}{|c|c|c|}
\hline \multirow[t]{3}{*}{ Input } & Actors related to problem situation & $\begin{array}{l}\text { Attitude } \\
\text { Mutual relationships }\end{array}$ \\
\hline & Actors involved in research & $\begin{array}{l}\text { Attitude } \\
\text { Willingness to cooperate } \\
\text { Availability } \\
\text { Expertise } \\
\text { Motives } \\
\text { Mutual relationships }\end{array}$ \\
\hline & Availability of resources & $\begin{array}{l}\text { Time } \\
\text { Funds } \\
\text { Supporting tools }\end{array}$ \\
\hline \multirow[t]{7}{*}{ Content } & Adequacy of methodology & \\
\hline & Depth & \\
\hline & Broadness & \\
\hline & Validity, credibility & $\begin{array}{l}\text { Use of state-of-the-art knowledge } \\
\text { Consistency, coherence } \\
\text { Attention for uncertainty } \\
\text { Precision }\end{array}$ \\
\hline & Quality of argumentation & \\
\hline & Relevance & \\
\hline & Handling the values of stakeholders & \\
\hline \multirow[t]{5}{*}{ Process } & Actors involved in the analysis & $\begin{array}{l}\text { Reason for involvement } \\
\text { Representativeness } \\
\text { Extent of participation and cooperation } \\
\text { Openness } \\
\text { Commitment }\end{array}$ \\
\hline & Organization & $\begin{array}{l}\text { Flexibility } \\
\text { Transparency } \\
\text { Goal orientation } \\
\text { Clarity of structure }\end{array}$ \\
\hline & Working methods & $\begin{array}{l}\text { Activating, barrier removing } \\
\text { Openness, democratic nature } \\
\text { Legitimacy } \\
\text { Match with culture } \\
\text { Taking participants seriously }\end{array}$ \\
\hline & Efficient use of resources & $\begin{array}{l}\text { Time } \\
\text { Money } \\
\text { Personnel }\end{array}$ \\
\hline & Communication & $\begin{array}{l}\text { Frequency } \\
\text { Form } \\
\text { Who with whom } \\
\text { Openness } \\
\text { Richness and relevance } \\
\text { Relevance of nonverbal communication } \\
\text { Clarity } \\
\text { Balance in participation }\end{array}$ \\
\hline
\end{tabular}




\begin{tabular}{|c|c|c|}
\hline \multirow[t]{8}{*}{ Results } & Consistency & \\
\hline & Verifiability, validity & \\
\hline & Extensiveness of documentation & \\
\hline & Relevance & $\begin{array}{l}\text { Consideration of all interests } \\
\text { Match with policy process } \\
\text { Potential value to the parties }\end{array}$ \\
\hline & Presentation & \\
\hline & Availability & \\
\hline & Acceptance by parties at interest & \\
\hline & Solutions presented (variety) & \\
\hline \multirow[t]{4}{*}{ Use } & Which elements & \\
\hline & By whom? & \\
\hline & For what purpose? & \\
\hline & Long-term vs. explicit use & \\
\hline \multirow[t]{4}{*}{ Effects } & Policy Process & $\begin{array}{l}\text { Decision time } \\
\text { Breaking deadlock }\end{array}$ \\
\hline & Implementation & \\
\hline & Problem situation & \\
\hline & Actors related to the problem situation & $\begin{array}{l}\text { Learning effects } \\
\text { Consensus reaching } \\
\text { Commitment to results } \\
\text { Communication patterns and negotiation } \\
\text { Balance of power }\end{array}$ \\
\hline
\end{tabular}

or environment-related projects on the Incomati River (Tables 2 and 3).

Of primary importance to the validity of the research is the fact that the interviews were conducted by a Dutch student with no affiliation to any of the countries involved and no national bias. This, together with the assurance that respondents could remain anonymous in the reporting of the study, facilitated open verbal communication about the problems associated with decision making on the Incomati.

Mostert (1998) comments that a decision-making perspective on river-basin management is necessarily subjective. Accordingly, the factual statements made during interviews were checked for validity with documentary sources and with other respondents during subsequent interviews, but differences in the subjective perceptions of the respondents regarding the transnational decisionmaking process were viewed as equally valid. This means that respondents' statements regarding, for example, the motives or goals of other stakeholders in the process were treated as valid information, whereas statements regarding, for example, the presence of particular delegates or the date at which information was supplied to other stakeholders, were cross-checked. Owing to differing levels of involvement in the international decision making (see Table 2), not all interview questions were equally relevant to all respondents, nor could all assertions be checked comprehensively. Once the documented interviews had been confirmed as an accurate representation of the interview by each of the respondents, the actor-related information was 
Table 2. Categorization of respondents according to organizational affiliation and nationality/location.

\begin{tabular}{lccc}
\hline \hline Organizational Affiliation & South Africa & Mozambique & Swaziland \\
\hline National water organization & 4 & 6 & 3 \\
Regional water organization & 2 & 1 & 1 \\
Scientist & 4 & 1 & 1 \\
Consultants & 1 & & 1 \\
Stakeholders & & 2 & \\
International organization & & 2 & \\
\hline
\end{tabular}

analyzed. A sense-making lens derived from network-governance literature (particularly van Bueren et al. 2001) and more recent studies on collaboration in the management of socialecological systems (Nkhata et al. 2008) was used in this analysis. It comprised cognitive factors (at the level of the individual actor), social factors (the interactions of involved actors throughout the process), and situational factors (the institutional context). A causal analysis was then employed to highlight the complexity of the identified interactions. Finally, the broader implications of these findings for information-based decision making and the design of institutions to support this were explored.

\section{Background Information}

The Incomati River rises in the mountainous regions of Swaziland and South Africa, drops over the escarpment to the lowland areas of these countries, and crosses the Mozambican coastal plain, gaining major tributaries along the way (the Komati, Crocodile, Sabie, Massintonto, Uanetze, and Mazimechopes Rivers), before entering the sea at the northern extremity of Maputo Bay (Fig. 1). The river catchment forms a small part of one of the most developed areas in southern Africa, the Gauteng region, contributing some $60 \%$ of South Africa's economy. The river is a source of water and other ecological services to subsistence populations living adjacent to its banks. In addition, there are many areas of conservation importance within the basin, including the famous Kruger National Park. The Incomati Estuary is an important habitat for colonies of aquatic birds. It also is of significance for the spawning of species of prawn and, therefore, is economically important to Mozambique. The mainstays of the economy in the Incomati Basin are agriculture and forestry, with urban developments and mining activities occupying a secondary role. High water use in parts of the basin means that there is severe water stress during dry periods of the year and during years with below-normal rainfall and runoff (van der Zaag and Carmo Vaz 2002, Consultec and BKS Acres 2001). Therefore, water allocation is an important issue in the international water management of this river basin.

In all three countries, water use is regulated by a central water-management body within a particular ministry. This is the Department of Water Affairs and Forestry (DWAF) in South Africa, the National Water Directorate (DNA) in Mozambique, and the Water Resources Branch within the Ministry of Natural Resources and Mining in Swaziland. The day-to-day water allocation and management tasks are (to be) delegated to decentralized bodies that are constituted along hydrological boundaries (van der Zaag and Carmo Vaz 2002). These are the Catchment Management Agencies in South Africa and the River Basin Units within the Regional Water Administrations in Mozambique. Swaziland approved a new water act in 2003 that foresees the introduction of Regional Water Boards. 
Table 3. List of interview questions.

\begin{tabular}{|c|c|}
\hline Background information & $\begin{array}{l}\text { - Name and position of respondent } \\
\text { - Disciplinary background, working here since when } \\
\text { - Name of organization, department/division } \\
\text { - Date and time of interview } \\
\text { - Task of organization, task of respondent's division/sector }\end{array}$ \\
\hline $\begin{array}{l}\text { Involvement with the } \\
\text { Incomati }\end{array}$ & $\begin{array}{l}\text { - When did you start to become involved in the Incomati? Are you involved at an } \\
\text { international level? } \\
\text { - Who are your colleagues in the other countries? Are you satisfied with the way the } \\
\text { communication is going? If not, what are the problems? What do you think is the reason for } \\
\text { these problems? } \\
\text { - What is the most challenging part of your work, most challenging decisions? } \\
\text { - Who do you contact when you have a problem? } \\
\text { - Do you have a problem with getting the right information to do your job well? } \\
\text { - Wow far do you think language and cultural differences influence communication? } \\
\text { years? }\end{array}$ \\
\hline Joint Incomati Basin Study & $\begin{array}{l}\text { - Do you have a copy of the final report? Do you use it? } \\
\text { - How was the JIBS conducted? By whom? } \\
\text { - What is your opinion about the content? Was there discussion about the content? }\end{array}$ \\
\hline Shared Rivers Initiative & $\begin{array}{l}\text { - Have you heard of the Shared Rivers Initiative? } \\
\text { - Who was involved and why? } \\
\text { - What do you consider to be the Shared Rivers Initiative's main achievement? } \\
\text { - Why didn't the Shared Rivers Initiative have the effect it could have had at the international } \\
\text { negotiations? }\end{array}$ \\
\hline Compliance & $\begin{array}{l}\text { - What is the TIA requirement? Are the countries complying with the TIA? } \\
\text { - Tell me about the problems in the basin concerning droughts. } \\
\text { - How is the situation now in the river basin (dry/enough water)? }\end{array}$ \\
\hline Recent developments & $\begin{array}{l}\text { - Do you think all three countries are satisfied with the current new agreement (TIA)? Do } \\
\text { you think it will work? } \\
\text { - What do you think is the main problem issue in the Incomati River Basin? } \\
\text { - What do you think should be the main goal for the coming two years? } \\
\text { - What is your opinion about creating a River Basin Organization: objective and mandate/ } \\
\text { who/ financing/location /cooperation with the Dutch government/ twinning arrangements } \\
\text {-What is your opinion about an information-sharing platform? }\end{array}$ \\
\hline Summary question & $\begin{array}{l}\text { - What structure/measures would help in using information better in the decision-making } \\
\text { process? }\end{array}$ \\
\hline
\end{tabular}

\section{RESULTS}

\section{Historical Analysis}

Three phases may be distinguished in decision making on the Incomati River Basin.

\section{International decision making from 1964-1991}

The first turbulent phase extends from 1964-1991 and was heavily influenced by political developments in the region. On 13 October 1964, the governments of South Africa and Portugal signed the "Agreement in Regard to Rivers of Mutual Interest and the Cunene River Scheme." It is the oldest agreement relating to water management in the southern African region. In 1967, Swaziland acceded to Part 1 (Rivers of Mutual Interest). The agreement acknowledges the importance of rivers as water resources for the development of the respective national territories as well as the advantages of collaborating in their development (Cunene Agreement 1964). The first 
Tripartite Technical Conference on Rivers of Common Interest among South Africa, Swaziland, and Mozambique (with the latter two countries still under colonial rule) was held in Mbabane, Swaziland, in 1967. The full and free exchange of hydrological data was a subject of discussion even then. Two follow-up conferences were held in 1969 and 1972, but no recognizable progress was made in regard to data exchanges (van der Zaag and Carmo Vaz 2002). In 1968, Swaziland gained independence peacefully from Britain, and in 1975, the Popular Republic of Mozambique proclaimed its independence from Portugal, following the Lusaka Accords after some 10 years of war. The next tripartite meeting was held in 1982 after an impasse of 10 years. It is probable that the three countries experienced difficulties in meeting in the 1972-1981 period, owing to differences in political ideologies. Other reasons could include the sequence of floods and then drought affecting southern Africa during this period. Southern and central Mozambique experienced floods in 1975, 1977, and 1978. The flood that struck the lower Limpopo in 1977 and displaced an estimated 400 000 people was particularly devastating (Lumbroso et al. 2008). A severe drought in southern Africa followed, only ending when Cyclone Demoina struck the Incomati, Maputo, and Umbeluzi catchments, causing extensive damage in Swaziland, South Africa, and Mozambique (Munslow 1984).

The TPTC was officially established in 1983 . The TPTC comprises three representatives from each of the three countries and is convened on an ad hoc basis. All decisions are made by consensus. The TPTC can advise the three governments on water use and water policy related to the Incomati and other shared river basins (TPTC 1983). At the time of establishment, Mozambique and Swaziland reacted differently to the incentive of economic cooperation offered by South Africa, despite both countries having participated in setting up the TPTC (Turton 2003). Swaziland's strategy was highly opportunistic. By considering the existing water issues purely in terms of self-interest, Swaziland was able to create win-win outcomes for itself and South Africa. Mozambique, on the other hand, viewed the cooperation offered by South Africa more sceptically (against a backdrop of armed resistance within parts of Mozambique, funded by South African sources). Meanwhile, South Africa and Swaziland rapidly expanded their water use in the basin. In short, this phase was characterized by fragmented policy games with minimal political commitment where more than one decision-making round occurred. Some ended in an impasse, and some ended with agreements that were only beneficial to the participating parties.

Another important process was the formation of the Southern African Development Community Council (SADCC), later called the Southern African Development Council (SADC). This initiative initially united the countries in the region in an attempt to economically isolate the South African apartheid regime. Right at the outset (1987), the countries along the Zambezi River initiated discussions on the environmentally sound management of this common water course, drawing on the "Helsinki rules on the uses of the waters of international rivers" (International Law Association (ILA) 1966). This discussion platform formed the groundwork for the development of the "SADC Protocol on Shared Watercourses" (SADC 1995) at a later stage (in 1995 and in revised form in 2000).

Individually, the upstream countries of the Incomati (South Africa and Swaziland) needed cooperation from the downstream country (Mozambique) to obtain international financing for further development of the water resources of the basin (van der Zaag and Carmo Vaz 2002). In the more positive political climate following the release of Nelson Mandela from prison in February 1990 and the dismantling of apartheid in South Africa, this resulted in the signing of the so-called "Piggs Peak Agreement" in 1991. With this agreement, a minimum cross-border flow for Mozambique was established, and South Africa and Swaziland were able to start building the Maguga and Driekoppies dams. The JIBS was initiated with the aim of jointly establishing the cumulative effects of water use and proposed developments on the river (TPTC 1991).

\section{International decision making from 1991-2002}

The second phase in decision making about the Incomati River Basin runs from 1991-2002 and can be regarded as a period of improving relations. It culminated in the signing of the IIMA in 2002. Although it was disputed by downstream countries like Mozambique, the SADC Protocol (1995) provided the impetus for discussions regarding transboundary rivers in the region. This protocol was immediately revised and a new version entered into force in 2000, drawing heavily from the language contained in the UN" "Convention on the 
Law of the Non-Navigational Uses of International Watercourses" (UN 1997, Giordano and Wolf 2002). Furthermore, the World Summit on Sustainable Development in Johannesburg in August 2002 created a "policy window" (Kingdon 1984/1995). For the three Southern African nations, this event created the political support needed to conclude the negotiations.

During this phase, the countries slowly became acquainted. They created common terms during the JIBS and while working toward the IIMA. An international network developed, albeit a very rudimentary one. They also found ways to manage their uncertainties regarding the future and each other. By formulating the contours of an aspired outcome in the form of an interim agreement with a strong legal framework, but leaving room for adjustments when it came to numbers, "structural uncertainty" (Grünfeld 1999) was addressed. At the same time, information uncertainty was partially addressed by breaking down a single decision into a sequence of decisions over time, thereby embracing the principle of a phased or iterative approach. The initial decisions made on crossborder flows, for instance, were to be evaluated and refined in 2006 as more information became available.

\section{International decision making from 2002 to date}

The third round is the present one, which can be characterized as "cautious optimism." All three countries regard the IIMA as a "gentlemen's agreement" and a start for the future. It demonstrates their willingness to cooperate, but it is not the final result. Most parties realize that, given the current rate of development of the water basin, the timeframe for a comprehensive agreement as set by the IIMA is difficult and challenging. Whereas the previous rounds focused on making decisions, the challenge during this new round is implementation. In the past, compliance with international agreements often did not take place. Now, compliance (and mechanisms to monitor it) is essential. Commitment at the level of individual water users as well as national and regional water managers is essential for this. The intended outcomes of this phase are the creation of institutions for sharing water management at the operational level and the refinement of the IIMA in the form of a comprehensive trinational agreement.

\section{The Joint Incomati Basin Study}

In determining the effects of the Joint Incomati Basin Study (Phase I from 1992-1995, and Phase II from 2000-2001) on the negotiations preceding the signing of the IIMA, we followed Thissen and Twaalfhoven (2001) in analyzing the inputs to the study, the content and process of the study, the results, their use, and their effects (Table 1). The subsequent analysis is based on both the document analysis and information derived from the interviews (Table 3).

The JIBS was initiated by order of the TPTC, with initial funding from South Africa and later with international financial support, particularly for the Mozambican component. All the parties directly involved (the TPTC representatives and the technical experts employed) were positive and their attitude toward cooperation was cautiously open. However, the Mozambican component of the study was delayed for approximately 5 yrs, because the upper echelons of the Mozambican government were not willing to commit to a collaborative study. This initial lack of political commitment on the part of the Mozambican government was probably related to the South African funding source. At the same time, Mozambique was gaining experience in negotiating with multiple countries along the Zambezi River. For the overall analysis, it means that the data from Swaziland and South Africa are not contemporaneous with those from Mozambique. However, within the TPTC, the three countries decided together in a democratic manner on the content of the research, and information was provided more or less freely to the other countries, particularly in the latter stages. A broad range of issues was covered by the study, focusing on the cumulative impact of developments in the Incomati Basin. However, potentially sensitive issues (e.g., environmental flow requirements or water abstractions) were not addressed in depth. The consensual manner of working had the advantage of building a degree of trust and removing some of the historically based barriers to working together. The presentation of the results of the JIBS was comprehensive and clear. The negotiations for the IIMA were already underway when the JIBS was finalized and this mismatch in timing meant that the elements of the JIBS relating to the water requirements of Mozambique and the Incomati Estuary in particular, were not able to be used in the negotiations. In addition, not all the results were accepted unequivocally by the countries involved. 
This partial acceptance of the results remains a weak aspect of the JIBS (Consultec and BKS Acres 2001, van der Zaag and Carmo Vaz 2002). One recommendation taken seriously is the advice to review the current institutional structure.

In summary, the JIBS cannot be said to be responsible for breaking deadlocks or reducing decision time. Even with such a detailed study of the Incomati River's water resources, the watersharing agreement took much longer to achieve than initially envisaged (that is, 3 yrs of tedious negotiations). The results of the JIBS do not seem to have influenced the cross-border flows agreed upon in the IIMA. However, the value of the JIBS as a common point of departure and a shared learning process should not be underestimated. Although the results of the JIBS may not be fully accepted, the practice of working together, albeit warily, became the norm. Indeed, a similar process has been followed for many other rivers (e.g., the Pungue, Umbeluzi, and Maputo systems).

\section{Information Issues}

Several problems with information in the international decision-making process on the Incomati river basin in the period 1991-2002 (during both phases of the JIBS) were identified based on the interviews. Specifically:

1. Reliable data on water abstractions from the river system are lacking. Information on water abstractions is based on the permissible abstraction volume (regulated by means of permits) or on calculations based on surface areas per land-use type. There are very few hydrological-flow stations in place and, with the exception of South Africa, the hydrological networks need improvement. This lack of data and the unreliability of the existing data mean that the parties involved do not always trust the data provided.

2. There is a lack of knowledge about the existing written information. There are only a few copies of most reports in existence and these are difficult to obtain. Additionally, a phenomenon mentioned by several interviewees is that most of the research reports are not widely read or used, but end up on a shelf. Accordingly, there is no shared knowledge base.
3. The hierarchical structure of the national water networks means that in general there is a time delay of several months before hydrological data from the field can reach policy makers. However, appropriate information was accessed rapidly, processed, and used effectively during the March 2000 floods. This implies that the capability to use data effectively is present, but that willingness is based on a sense of urgency, and a precise knowledge of the type of data required needs to be present for this capability to be activated.

4. There is a suspicion of, and resistance to, unsolicited research. This is most evident in the attitude of interviewees to results from a trinational collaborative research program (the Shared Rivers Initiative). Whereas the JIBS is regarded as a comprehensive report that the involved parties agree with to a greater or lesser extent, the research initiative on the part of South African, Swazi, and Mozambican scientists is regarded as interference. Accordingly, little use has been made of the excellent results of this research by decision makers on the TPTC.

5. There is a failure to select and filter information for communication and decision making. This is particularly true for water managers in Mozambique who are fully aware of the lack of reliability of the basic data and feel the need to collect ever more data. This focus on basic data hampers them in moving beyond data uncertainty to the implications of flows for river functioning and the associated decision making. A complicating factor in this regard is that there is no separation at the TPTC level between communication about basic data and the discussion of higher level matters such as the degree of water abstraction or future development plans. There are also no agreedupon policy indicators.

6. There is no agreed-upon process in place to monitor cross-border flows, nor to enforce compliance with international treaties. The only pressure to comply is moral pressure, or hopefully in the future, the presence of the SADC Tribunal. This means that negotiations regarding cross-border flows are inherently 
based more on intuition and suspicions than on actual information.

In summary, there is no shared basic data set, no shared basic knowledge, and no agreed-upon means of synthesizing and processing data, combined with distrust about other parties' intentions.

\section{CAUSAL ANALYSIS}

The discouraging nature of these findings could lead one to conclude that immediate action should be taken to improve the provision, reliability, and use of basic data. This is necessary, of course, but it does not address the fact that despite the increase in the provision and quality of basic data from 1964 to the present, information use still remains a problem. By adopting an interpretive framework from network governance theory (van Bueren et al. 2001), we are able to distinguish three groups of interrelated factors. These are "cognitive" (at the individual actor level), "social" (at the level of interaction among actors, including the negotiation processes), and "situational" (the organizational context and institutional rules and norms within which the interactions occur). These three factors lie at the root of the identified information issues (Fig. 2). We follow Nkhata et al. (2008) in identifying the role of the past experiences of actors, and their current interactions and expectations as influencing their sociopsychological state. Indeed, we concur with their analysis of the role of relational capital and relational connectedness in influencing collaboration in the management of the water resources of the Incomati River. However, in contrast to Nkhata et al. (2008) we explicitly include the role of contextual factors (i.e., situational factors) in mediating this influence. We demonstrate the complexity of these interactions using a causal analysis of the information derived primarily from the interviews.

First, we distinguish cognitive causes such as the influence of perceptions and cultural differences. The existing discrepancies in perception are intricately linked to the history of apartheid. South Africa and Mozambique have a paradoxical relationship. The South Africans are in a complex position. If they take the lead in the decision-making process, they confirm the "big-brother" image that Swaziland and Mozambique had developed of them during the apartheid period. However, South Africa is the most developed country of the three and has the greatest capacity to initiate information-based decision making. The South Africans have the feeling that if they don't act, things will happen slowly or not at all. This also influences the different perspectives the countries hold on the implementation of the IIMA. Mozambique, traditionally the underdog, is actually in a potentially beneficial position now that South Africa is trying to demonstrate goodwill to the surrounding countries. Perceptions are also influenced by the fact that there is little opportunity for cross-national personal contact. The memories of the past, and the way the countries act accordingly, also influence the trust the countries have in each other.

Secondly, there are social causes that influence decision making and the use of information. The lack of (national) stakeholder involvement at the international level means that certain information is not available at this level of decision making. This may have consequences for the implementability of international decisions, because the willingness of individual water users or national stakeholder groupings to commit to water sharing is essential, especially when it comes to managing water abstractions in times of drought. The commitment of the southern African countries to maintaining their sovereignty means that political integration is not desired. Decisions are made at a very high level in the hierarchy and there is a lack of devolution of decision-making power from ministerial to lower levels and to the TPTC. This causes information delays, and delegations lack the mandate to make decisions themselves, causing frustration at the TPTC level. This is closely related to the presence or absence of political commitment. Additionally, the lack of a common language forms a barrier to communication.

Cognitive and social causes are deeply linked to institutional or situational causes in this case, because perceptions and cultural differences also influence the creation of shared rules, norms, and values. First, there is no joint "hydrometric network" that influences information access and use. At the time of the study, the absence of administrative support in the form of a simple permanent TPTC secretariat did not improve this situation. The presence of such a secretariat could have improved the exchange of information and the quality of information management and, therefore, the use of technical information in the functioning of the TPTC. In the Incomati Basin, a lack of capacity is experienced in several ways. In all three countries, trained employees leave the public 
Fig. 2. Causal diagram of issues in the decision-making process on the Incomati River Basin. Factors of influence are placed in an oval. An arrow means a causal influence. The sign indicates whether a factor increases (+) or decreases (-) as the result of an increase in the source factor.

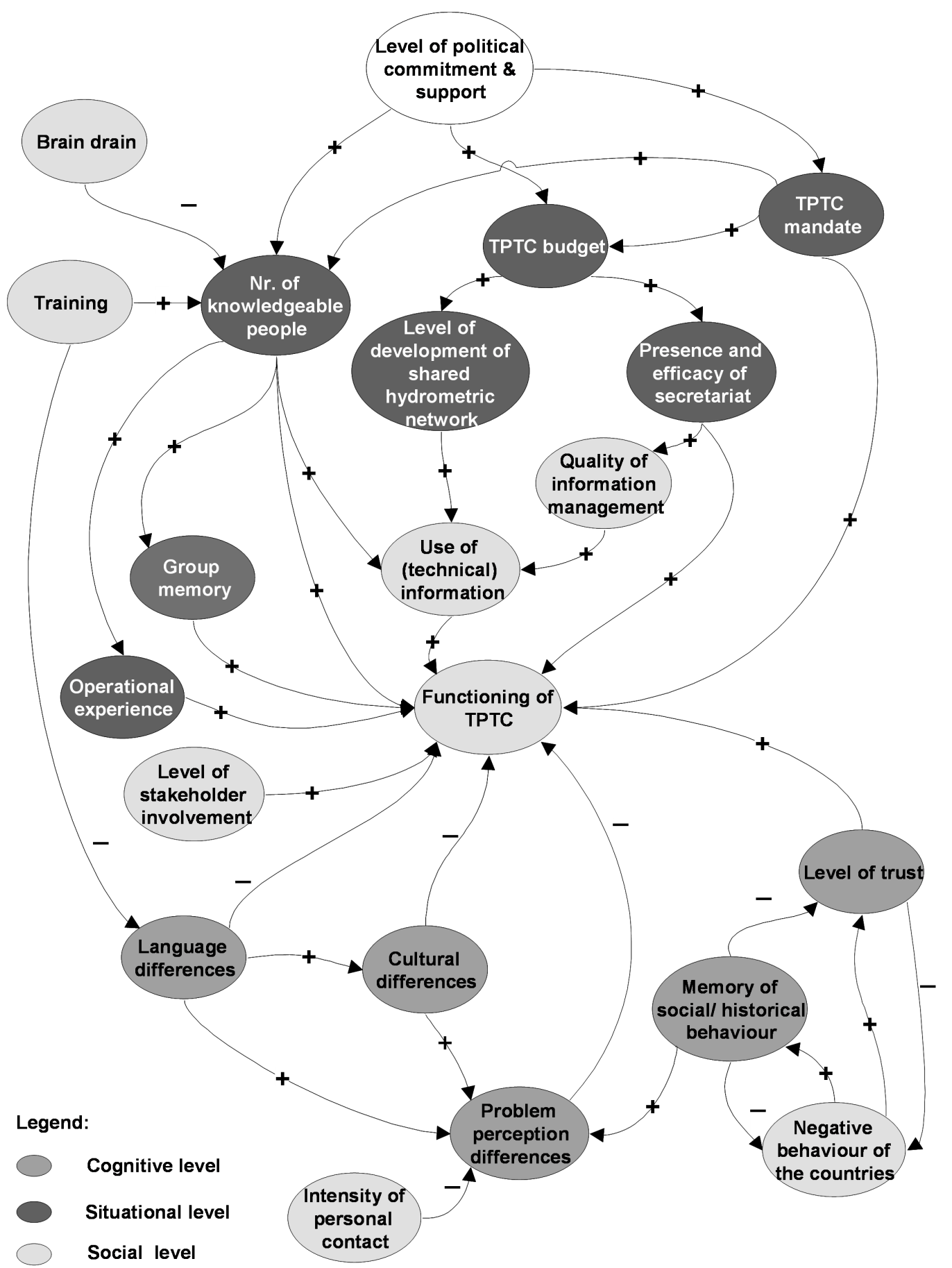


service or the country itself because of low salaries and the impossibility of applying their skills effectively in their work. This "brain drain" is a phenomenon that is experienced by many developing countries. It results in a lack of "group memory" and in this case, it means that the TPTC lacks sufficient knowledgeable people with operational experience. Training will be needed in the future. Additionally, delays associated with translation were mentioned as a problem by both the South Africans and the Mozambicans.

Finally, the TPTC is a relatively weak institution in that it cannot control the policy process related to the Incomati. The TPTC lacks financial capacity. The TPTC itself has no budget and does not have the mandate to attract funds. It is dependent on each of the representatives sourcing funding from their home organization for meeting attendance and TPTC management activities. This means that for many projects, there is no single source of funding, splintering efforts and costing time.

\section{DISCUSSION}

Clearly, there is more at play here than just problems with information. Even the identification of the interrelationships between the cognitive, social, and situational factors cannot fully explain why information provision and use have remained problematic issues in international decision making on the Incomati River Basin. The improvement in the understanding of water management over the last 40 years, encapsulated in the concept of "integrated water-resources management," has been adopted successfully in the Incomati basin, at least on paper, as evinced by the IIMA. Why then, despite better gauges, more measurements, improved data-processing procedures, and advances in hydrodynamic modeling and ecological concepts, has information and its use remained problematic over this 40-yr period? The concept of decision making as a purely rational activity based on the best available information would preclude this occurring. Can we offer a better explanation?

De Kok and Wind (2003) note that a controversial assumption about information use in decision making is that of bounded rationality. The underlying assumption is that the quality of decision making can be improved if a decision maker is given additional information about the consequences of his actions. This optimistic view is not always supported by evidence from the past, which shows that too often, solutions were selected that had no relation to the objectives or to the problem. Indeed, many decisions in water management are still politically motivated (De Kok and Wind 2003). Within the NeWater project (an integrated project in the $6^{\text {th }}$ Framework Programme of the European Union), researchers conclude in a policy note that "the management of transboundary water is therefore inherently political, and the political will from the governments of all riparian countries is a prerequisite for successful initiation and continuation of any transboundary cooperation" (Timmerman and Interwies 2007).

Network theory tells us that policy making or decision making takes place in a network of interdependent stakeholders or actors (Koppenjan and Klijn 2004, Rhodes 1996, Klijn 2008). The network model is based on the idea that actors are interdependent and that a policy-making process can only be effective through cooperation. In this view, policy making looks like a series of negotiation rounds. The result differs per round and the outcome is not foreseeable. The decisionmaking process is characterized by zigzagging and iterations, with different activities taking place at the same time and linking in different ways (Kingdon 1984/1995, Lindblom 1993, De Bruijn and Ten Heuvelhof 1999). Actors may begin to cooperate when they have the same objectives, see possibilities for exchange, or when they are being stimulated (or controlled) by an external authority. The emergence of cooperation or conflict is heavily influenced by actors' different perceptions of each other and the problem issues. Perceptions are based primarily on the resources and information an actor has or lacks relative to other actors (Meijerink 1999).

Network theory allows us to understand that data and information are nonneutral and instead are actor-related. It is this aspect of information use within decision-making processes that, in our opinion, lies at the core of the 40-yr problem with information in the Incomati River Basin. Whereas many would argue that the problems with information experienced in the Incomati Basin are related to a lack of capacity to use it, our analysis of the JIBS has revealed that a distrust of the way the information may be used and a consequent lack of political will to engage can be an underlying cause. This translates to low "relational capital" and "relational connectedness" (Nkhata et al.2008) and, 
hence, limited collaboration in the management of the water system.

According to De Bruijn and Ten Heuvelhof (1999), for information to be useful in a decision-making network, it needs to have the status of "negotiated knowledge." Negotiated knowledge in policy processes is the product of mutual interactions (within policy circles) leading to agreement on the meaning and interpretation of accessible information. This is not necessarily the same as socially constructed knowledge, which is the fruit of an open negotiation process (Habermas 1984). This would mean that, for significant progress to be made in the implementation and refinement phases of the IIMA, attention needs to be given to generating negotiated knowledge about the Incomati River Basin.

De Bruijn et al. (1998) identify two essential design principles for the use of knowledge or technical expertise in the policy-making process that are based on network theory. First, insight derived from such knowledge should be used in a facilitating way. The roles of experts and decision makers or stakeholders should be interwoven and yet separate. The idea is to let experts participate in the process, to give them the autonomy to conduct research as independent experts, but also to let experts and decision makers or stakeholders interact regularly. In this way, experts can influence the quality of the decision-making process and the research can be adjusted to actual needs. Secondly, a pattern from information variety to selection should be sought. Variety is a guarantee that all opinions are recognized, and selection is needed to bring focus. In general, the guiding principle is that "as long as actors are still learning, it is useful to generate variety, if stabilization takes place it is time for selection" (De Bruijn et al. 1998). Two assumptions underlie these design principles. The first is that there are experts separate from decision makers or stakeholders, i.e., that multi-level structures and interactions are possible. The second is that open discussion of issues is welcome and possible. Both assumptions do not hold fully in the case of the Incomati River Basin. This is so in the former case because a lack of capacity in water-resources management-particularly in Mozambique and Swaziland-means that the roles of expert and decision maker are often held by one person. The latter is true because open discussion requires a culture that facilitates this. In responding to the questions concerning communication and culture in relation to their work, interviewees indicated that the space for intercultural communication as promoted by Lie (2003) was not present within the TPTC (Table 3). As such, the design principles should be used as a stimulus for creative situationspecific design that takes the existing culture into account, rather than as rigid guidelines.

\section{CONCLUSIONS}

Central to this study is the issue of information use and its influence on the past, present, and future functioning of the TPTC. A water-management body functions well when it can develop effective and efficient water-sharing rules and operate the system accordingly (Savenije and van der Zaag 2000). From the causal analysis, we can conclude that the functioning of the TPTC could be improved if two groups of factors were to positively change:

1. The situational factors, that is, the institutional arrangements (mandate, budget, hydrometric network, operational experience, etc.).

2. The cognitive factors, and in particular, the perceptions each country holds of the other and the way they treat one another.

Any new institutional arrangements for the management of the Incomati Basin at the international level should have at least the following elements to be able to support the implementation of the IIMA: a broader mandate, an adequate budget, a secretariat, a shared hydrometric network and database, greater information management, an operational focus, and more stakeholder involvement. An institutional design with a structured way of dealing with information transfers (i.e., institutional rules) and a dual focus on operational as well as political matters is advisable. These structures can be created in many ways (two extremes being in a top-down fashion, e.g., a supranational River Basin Organization, or in a bottom-up fashion by organically growing or expanding existing regional water-management arrangements). We have resisted the request of many interviewees for suggestions on the type of institutional structure suitable for the Incomati. It is our conviction that with the insights contained in this analysis regarding both the constraints on information use and the necessity of fostering the development of negotiated 
knowledge as a basis for decision making, southern Africans can best design workable institutional arrangements for themselves.

However, merely adapting the institutional arrangements is not sufficient to improve the functioning of the TPTC. As discussed earlier, the culture of collaboration within the new structures also needs attention. The current atmosphere of cooperation between the countries and the willingness of the involved people to make things work are good starting points for making such changes. More personal contact between the TPTC delegates and the operational managers from the different countries is needed to develop trust and reduce problems of differences in perception. This implies increasing relational capital and connectedness, creating more understanding of cultural differences, and making it easier to deal with negative memories from the past.

Clearly, the institutional arrangements for the Incomati should address the sociotechnical competence required for day-to-day management, as well as knowledge generation, together with the sociopolitical competence required to acquire and sustain the commitment at the political level within each country. We are of the opinion that it is only by designing institutions with both a sociotechnicalexpertise focus and a sociopolitical focus that some of the fundamental problems of information use in decision making can be addressed.

Responses to this article can be read online at: http://www.ecologyandsociety.org/vol15/iss 1/art1/responses/

\section{Acknowledgments:}

We extend sincere thanks to the respondents in Mozambique, South Africa, and Swaziland who shared valuable information and their experience regarding decision making on the Incomati River with us. This research could not have been undertaken without the financial and practical support of the University Fund Delft, the Faculty of Technology, Policy and Management of Delft University of Technology, the Committee Study and Travel Fund of the Royal Institution of Engineers in the Netherlands, and the Council for Scientific and Industrial Research in South Africa. We thank the anonymous reviewers for insightful comments on previous versions of the paper.

\section{LITERATURE CITED}

Consultec, and BKS Acres. 2001. Joint Incomati Basin study phase 2. Report to the Tripartite Permanent Technical Committee; Kingdom of Swaziland-Republic of Mozambique-Republic of South Africa. April 2001.

Cunene Agreement. 1964. Treaty on rivers of mutual interest. 13 October 1964. Lisbon, Portugal.

De Bruijn, J. A., and E. F. Ten Heuvelhof. 1999. Management in netwerken. Lemma BV, Utrecht, The Netherlands.

De Bruijn, J. A., E. F. Ten Heuvelhof, and R. In 'tVeld. 1998. Procesmanagement: over procesontwerp en besluitvorming. Academic Service, Schoonhoven, The Netherlands.

De Kok, J. L., and H. G. Wind. 2003. Design and application of decision-support systems for IWM: lessons to be learnt. Physics and Chemistry of the Earth 28:571-578.

Enserink, B., M. Patel, N. Kranz, and J. Maestu. 2007. Cultural factors as co-determinants of participation in river basin management. Ecology and Society 12(2): 24. [online] URL: http://www.e cologyandsociety.org/vol12/iss2/art24/

Giordano, M.A., and A. T. Wolf. 2002. The world's international freshwater agreements. United Nations Environment Programme (UNEP), Nairobi, Kenya.

Grünfeld, H. 1999. Creating favorable conditions for international environmental change through knowledge and negotiation: lessons from the Rhine Action Program and the Second Sulphur Protocol, implications for climate change. Delft University Press, Delft, The Netherlands.

Habermas, J. 1984. The theory of communicative action. Beacon, Boston, Massachusetts, USA.

International Conference on Water and the Environment (ICWE). 1992. The Dublin statement and report of the conference. 
International Conference on Water and the Environment: development issues for the $21^{\text {st }}$ century. 26-31 January 1992, Dublin, Ireland.

International Law Association (ILA). 1966. Helsinki rules on the uses of the waters of international rivers. ILA, Helsinki, Finland.

Kingdon, J. W. 1984/1995. Agendas, alternatives and public policy. Little, Brown and Company, Boston, Massachusetts, USA.

Klijn, H. E. 2008. Governance and governance networks in Europe: an assessment of ten years of research on the theme. Public Management Review 10(4):505-525.

Koppenjan, J., and E. H. Klijn. 2004. Managing uncertainties in networks. Routledge Taylor and Francis Group, Florence, Kentucky, USA.

Lejano, R., and H. Ingram. 2007. How social networks enable adaptation to system complexity and exteme weather events. Pages 249-262 in C. Pahl-Wostl, P. Kabat, and J. Moltgen, editors. Adaptive and integrated water management: coping with complexity and uncertainty. Springer-Verlag, Berlin and Heidelberg, Germany.

Lie, R. 2003. Spaces of intercultural communication: an interdisciplinary introduction to communication, culture, and globalizing/localizing identities. Hampton Press, Creskill, New Jersey, USA.

Lindblom, C. E. 1993. The policy making process. Third edition. Prentice Hall, London, UK.

Lumbroso, D., Ramsbottom, D., and M. Spaliveiro. 2008. Sustainable flood risk management strategies to reduce rural communities' vulnerability to flooding in Mozambique. Journal of Flood Risk Management 1:34-42.

Meijerink, S. V. 1999. Conflict and co-operation on the Scheldt river basin: a case study of decisionmaking on international Scheldt issues between 1967 and 1997. Kluwer, Dordrecht, The Netherlands.

Mostert, E. 1998. Perspectives on river basin management. Physics and Chemistry of the Earth 24(6):563-569.
Mostert, E., C. Pahl-Wostl, Y. Rees, B. Searle, D. Tabara, and J. Tippet. 2007. Social learning in European river basin management: barriers and fostering mechanisms from 10 river basins. Ecology and Society 12(1): 19. [online] URL: http://www.e cologyandsociety.org/vol12/iss1/art19/

Munslow, B. 1984. State intervention in agriculture: the Mozambican experience. The Journal of Modern African Studies 22(2):199-221.

Nkhata, A. B., C. M. Breen, and W. A. Freimund. 2008. Resilient social relationships and collaboration in the management of social-ecological systems. Ecology and Society 13(1): 2. [online] URL: http:// www.ecologyandsociety.org/vol13/iss1/art2/

Pahl-Wostl, C. 2007. Requirements for adaptive water management. Pages 1-22 in C. Pahl-Wostl, P. Kabat, and J. Moltgen, editors. Adaptive and integrated water management: coping with complexity and uncertainty. Springer-Verlag, Berlin and Heidelberg, Germany.

Raadgever, T., E. Mostert, N. Kranz, E. Interwies, and J. G. Timmerman. 2008. Assessing management regimes in transboundary river basins: do they support adaptive management? Ecology and Society 13(1): 14. [online] URL: http://www.ecolog yandsociety.org/vol13/iss1/art14/

Rhodes, R. A. W. 1996. The new governance: governing without government. Political Studies 44:652-667.

Savenije, H. H. G., and P. van der Zaag. 2000. Conceptual framework for the management of shared river basins; with special reference to the SADC and EU. Water Policy 2:9-45.

Slinger, J., and M. de Groen. 2001. Programme on the management of the Incomati River Basin and adjacent coastal zone: a partnership between Mozambique, South Africa, Swaziland and the Netherlands. Resource Analysis Report RA/01-495. Delft, Netherlands. August 2001.

Southern African Development Community (SADC). 1995. Protocol on shared watercourse systems in the Southern African Development Community. SADC, August 1995, Gaborone, Botswana. 
Thissen, W.A. H., and P. G. J. Twaalfhoven. 2001. Towards a conceptual structure for evaluating policy analytic activities. European Journal of Operational Research 129:627-649.

Timmerman, J. G., and E. Interwies. 2007. Transboundary regimes and the role of information. NeWater Policy Brief No. 5, November 2007. [online] URL: http://www.newater.uos.de/intern/se ndfile.php?id $=\overline{58}$

Tripartite Permanent Technical Committee (TPTC). 1983. Agreement between the government of the Republic of South Africa, the government of the Kingdom of Swaziland and the government of the people's Republic of Mozambique relative to the establishment of a Tripartite Permanent Technical Committee. TPTC, 17 February 1983, Pretoria, South Africa.

Tripartite Permanent Technical Committee. 1991. Piggs Peak agreement. Signed at the Tripartite Ministerial Meeting of Ministers Responsible for Water Affairs. Fifteenth TPTC, February 1991, Swaziland.

Tripartite Permanent Technical Committee. 2002. Tripartite interim agreement between the Republic of Mozambique and the Republic of South Africa and the Kingdom of Swaziland for cooperation on the protection and sustainable utilisation of the water resources of the Incomati and Maputo watercourses. Resolution of the Tripartite Permanent Technical Committee on exchange of information and water quality. TPTC, 29 August 2002, Johannesburg, South Africa.

Turton, A. R. 2003. The evolution of water management institutions in selected southern African international river basins. Pages 251-289 in C. Tortajada, O. Unver, and A. K. Biswas, editors. Water and Regional Development. Oxford University Press, London, UK.

United Nations (UN). 1997. Convention on the law of non-navigational uses of international watercourses. UN, 21 May 1997.

United Nations Conference on Environment and Development (UNCED). 1992. Rio Declaration on Environment and Development. The final text of agreements negotiated by governments. UNCED, 3-14 June 1992, Rio de Janeiro, Brazil. van Bueren, E., E. H. Klijn, and J. F. M. Koppenjan. 2001. Spelen met weerbarstige problemen: het beleidsspel rond emissies van zink uit bouwmaterialen. Beleidswetenschap 2:141168.

van der Zaag, P., and A. Carmo Vaz. 2002. Sharing the Incomati waters: co-operation and competition in the balance, from potential conflict to co-operation potential. Final text, 11 December 2002, Maputo and Harare, Mozambique and Zimbabwe. 